\title{
LAS MUJERES EN LA ACTIVIDAD ECONÓMICA EN ARGENTINA, BOLIVIA Y PARAGUAY*
}

\author{
Zulma Recchini de LATtes \\ Centro de Estudios de Población (CENEP), Buenos Aires, Argentina
}

\section{INTRODUCCIÓN}

LA LITERATURA EXISTENTE sobre las relaciones entre participación femenina en el mercado de trabajo y desarrollo económico no han mostrado, hasta ahora, resultados concluyentes, si bien se viene destacando cada vez más lo que últimamente ha dado en llamarse la Curva en U. ${ }^{1}$ Esta no es más que una generalización empírica sobre las relaciones observadas entre el nivel de desarrollo económico y el grado de participación femenina en actividades económicas. Para decirlo de manera muy esquemática, la curva en $U$ describiría una pauta de participación relativamente alta en los estadios tempranos y tardíos del desarrollo y relativamente baja en los intermedios.

El descenso de la participación en las primeras etapas del desarrollo por lo general es "explicado" por la disminución de tareas agrícolas y artesanales (por innovaciones tecnológicas), en que las mujeres tienen amplia participación, en gran parte porque esas tareas no demandan una ruptura entre el papel doméstico y el económico, ya que son normalmente desarrolladas en el ámbito hogareño. $O$ sea, un cambio en la estructura socioeconómica del sentido indicado con seguridad desplazaría mujeres del mercado de trabajo.

Por otra parte, la fase ascendente de la curva tendría que ver, según constataciones empíricas, con una mayor inserción de las mujeres en el sector terciario, sector que se expande de manera considerable en etapas avanzadas del desarrollo económico.

Pero los resultados no son de manera alguna coincidentes. Ya Leser había señalado en 1958 que si bien la fase de descenso entre los estadios temprano e intermedio podría afirmarse que es universal, no sucede lo

* Esta investigación ha sido auspiciada por el Centro Internacional de Investigaciones para el Desarrollo (cm) bajo contrato No. 3-9-76-0009-02.

i Para una revisión bibliográfica sobre el tema, a nivel mundial y en particular sobre América Latina puede verse Recchini de Lattes y Wainerman (1977). 
mismo con la fase ascendente, ya que habría encontrado varios ejemplos que prevendrían la generalización. Casi veinte años más tarde Durand (1975) encuentra excepciones no sólo a la fase ascendente, sino también a la descendente, al encontrar, al igual que Pantelides (1976), en estudios de pseudo tendencia para América Latina, una asociación siempre positiva a lo largo de los diferentes estadios de desarrollo económico y que las pautas de cambio no eran claras en el análisis diacrónico.

Como surge del breve panorama trazado en los párrafos anteriores, la curva en $U$ no presenta, por un lado, una base teórica real que explique por qué y cuáles serían las variables que estarían actuando en una etapa y otra para resultar en una alta o baja participación y, por otro, tampoco las evidencias empíricas parecen ser coincidentes. Es ya muy frecuente en la temática sobre la participación femenina en el mercado de trabajo, achacar la falta de resultados satisfactorios a la mala calidad de las estadísticas básicas con las que se trabaja. Se podría agregar que, en el estudio de la relación que ahora nos ocupa, tampoco se ha tenido especial cuidado en definir o medir el otro término de la relación: desarrollo económico. Sin negar la importancia del uso de definiciones comparables para arribar a resultados fidedignos - lo que en general podrá tenerse en cuenta (en lo que hace a la mano de obra) para las próximas captaciones de datos, aunque son difícilmente superables para los estudios de tendencias históricas- existe otro camino para avanzar en el conocimiento de esta temática, cual es la línea sugerida entre otros, por Collver y Langlois (1962), Boserup (1970 y 1975) y desde mucho antes por Leser (1958), cuando observan que el cambio en los niveles de participación no se da ni en todas las ramas ni en todas las ocupaciones por igual. En efecto, es frecuente la observación de que mientras disminuyen, por ejemplo, las ocupaciones agrícolas y las de obreras artesanales, al mismo tiempo aumentan algunas de las "modernas", como las profesionales o las de vendedoras en comercios. De esta manera, la curva de participación femenina sería un agregado de diferentes curvas - cada una de las cuales correspondiente a una rama o una ocupación específica-, donde unas disminuirían y otras aumentarían con los cambios que se producen en la estructura económica.

$O$ sea, que la desagregación de la curva de participación total en sus componentes sectoriales $\mathbf{u}$ ocupacionales arrojarían luz sobre mecanismos de la estructura económica que están actuando frente a un fenómeno de cambio en los niveles de participación. De la misma manera, si se consideran otras variables que tienen que ver ya sea con la demanda, ya sea con la oferta de mano de obra, al desagregar las curvas de participación total a lo largo de distintos valores de esas variables, podrá observarse que la curva total obtenida puede ser el resultado de múltiples combinaciones de tendencias. $O$ sea, considerar sólo la tendencia en la participación total puede ocultar las de los componentes, que es necesario conocer para interpretar de manera correcta la total. En otras palabras, si se observa, por ejemplo, un aumento o una disminución en 
la tasa refinada de participación, ¿qué mujeres son las que están cambiando sus propensiones a participar (en términos de edades, estatus civil y familiar, nivel de educación, área de residencia, etc., etc.)? ¿En qué lugares del mercado de trabajo se están insertando (en términos de ocupaciones, sectores, ramas, etc.)? Según sean las respuestas a estas preguntas, será la explicación del fenómeno.

En los párrafos que siguen se intentará desarrollar las variaciones posibles de la participación femenina en cuanto a distintos valores de algunas de las variables mencionadas.

La tendencia de la participación en el tiempo es muy diferente en los distintos tramos del ciclo vital. En las edades activas jóvenes, en las cuales tanto varones como mujeres están en alguna proporción completando su educación formal, la dirección del cambio (no así el nivel) no se diferencia mucho entre uno y otro sexo: la tendencia al descenso es clara en tanto el desarrollo social de una población permita a más jóvenes permanecer durante más tiempo dentro del sistema educativo. Sin embargo, si aumentan las oportunidades y está aumentando la participación femenina en general, puede suceder que aumente la participación en estas edades aunque se eleve el nivel educativo.

En el otro extremo, a edades avanzadas, uno y otro sexo tienden a bajar su participación con el avance de medidas sociales de retiro. Pero, entre las mujeres, a esta tendencia puede yuxtaponerse la contraria. En efecto, a pesar de las mejoras en los sistemas de retiro, puede darse un alza en las tasas de participación por la vuelta a la actividad que suele producirse cuando los hijos de las mujeres han alcanzado edades en que la atención de la madre no es tan indispensable. Es lo que sucedió, por ejemplo, en los Estados Unidos después de 1940.

Así, es probable que las tasas de las muy jóvenes y las de edades avanzadas disminuyan si son muy altas y es más difícil predecir la tendencia cuando en el punto de partida los valores son intermedios o bajos.

Donde tanto el nivel como la dirección de los cambios en la participación femenina registran diferencias muy significativas con respecto al comportamiento masculino es en edades adultas jóvenes - coincidentes con la edad al casamiento, el nacimiento y la crianza de los hijos- y en las maduras - cuando los hijos han alcanzado la adolescenciay suelen producirse cambios significativos en la composición por estado civil (por el pasaje del estado de casada al de viuda o separada, con las implicaciones sociales y económicas que esto trae aparejado). En estas etapas del ciclo vital pueden producirse cambios en distintas direcciones en cuanto a la participación en la actividad económica.

Así, lo que a nivel agregado puede interpretarse como un aumento o una disminución de la participación femenina a través del tiempo, puede ser en realidad, de nuevo, el resultado de tendencias diferentes y aún contrapuestas de los distintos tramos del ciclo vital. 
De manera similar, en la medida en que las actividades urbanas y rurales se especializan cada vez más en el sentido de concentrarse en las ciudades todas las actividades de transformación y servicios, debe esperarse que las curvas de participación rural disminuyan y las de participación urbana aumenten en relación con la especialización de las funciones de ambas áreas que se produzcan a lo largo del tiempo. Una vez más, la tendencia en la participación global puede ser un compuesto en que sus componentes presenten tendencias distintas.

De esta manera, podría seguirse con cada una de las variables que determinan o bien a la oferta o bien a la demanda de mano de obra femenina para entender cuál es el peso que cada una de ellas tiene en la evolución de la participación femenina a través del tiempo, factores que actuarán de manera diferente en las sociedades que se están desarrollando en el presente que en los países más avanzados, y de manera, diferente según el estilo de desarrollo seguido por cada uno de los países. En otras palabras, lo que se sostiene aquí es que para formular de manera adecuada la relación entre participación femenina y desarrollo económico, a más de definir adecuadamente cada uno de los términos de esa relación, será necesario desagregar los niveles de análisis mucho más de lo que se ha hecho en general hasta el presente, no sólo a nivel de las variables de la estructura económica, sino también en lo relativo a las variables demográficas, sociales y culturales.

Aquí, el objetivo principal es avanzar en el conocimiento de la relación entre participación femenina y desarrollo a través del análisis de la tendencia observada en Argentina, Bolivia y Paraguay desde la segunda posguerra hasta una fecha cercana al presente. Para este fin, se desagrega la curva de participación total en términos de variables que condicionan la oferta de mano de obra (tramos de edad, cohortes de nacimientos), la demanda (ocupaciones, estatus ocupacional) y la intersección de oferta y demanda (participación urbana y rural). De esta manera, se verá cada curva como "responsable", parcialmente, de la curva total de participación. La selección de variables está limitada a la disponibilidad de datos comparables a través del tiempo en los tres países estudiados.

Esta investigación se basa en tres estudios de casos realizados de manera coordinada con un diseño común de investigación. ${ }^{2}$ Por lo tanto, no se presenta un análisis exhaustivo de todos los aspectos abarcados por los estudios parciales, sino simplemente de los que se han considerado más relevantes. Para los detalles se remite a los informes ya citados sobre los tres países.

2 La investigación fue coordinada y dirigida por el equipo argentino, formado por Ruth Sautu, Catalina H. Wainerman y la autora del presente informe, el que está basado en los documentos de Brizuela de Ramírez y Schoemaker (1978), Torrez (1977) y Recchini de Lattes (1977). 


\section{LOS CASOS ESTUDIADOS: BREVE CARACTERIZACIÓN DEMOGRÁFICA Y SOCIOECONÓMICA}

Los tres casos estudiados presentan en común una tradición cultural latinoamericana (colonización hispana, básicamente), pero en esencia son también diferentes en cuanto a sus respectivas realidades económicosociales. Son amplias y marcadas las diferencias entre Argentina y los otros dos países. En efecto, cualquiera sea el criterio de clasificación económica y social que se use para los países latinoamericanos, uno y otros estarán, respectivamente, en el peldaño más alto y en uno de los más bajos o el más bajo -ya sea que compartan o no el rango entre ellos, según sea el conjunto de indicadores usados. ${ }^{3}$ Como la diferenciación básica entre Argentina por un lado y Bolivia y Paraguay por el otro es ampliamente conocida y aceptada, tanto dentro de la región como fuera de ella, parece ocioso recordar aquí algo más que las diferencias fundamentales, las cuales se resumen en el cuadro 1, para el periodo que abarca este estudio.

En cuanto a las características demográficas, puede verse que Argentina constituye un país con una población mucho más grande que la de Bolivia y Paraguay, aunque con tasas de crecimiento notablemente más bajas, sobre todo en comparación con Paraguay. (Esto a pesar de que Argentina recibe inmigrantes internacionales, mientras que Bolivia y sobre todo Paraguay, expulsan). Asimismo, su densidad es mayor que las de los otros países, diferenciándose también muchísimo en cuanto a la distribución espacial de su población. Argentina es un país eminentemente urbano (uno de los más urbanizados de la región y del mundo), mientras que los otros dos países estudiados son eminentemente rurales. En cuanto a la estructura de la población, como resultado de que éstos han mantenido casi sin alteración un elevado nivel de fecundidad, presentan pirámides de edades muy jóvenes, mientras que Argentina, con menor nivel de fecundidad, por consiguiente presenta pirámides más envejecidas en todas las fechas observadas.

También los indicadores socioeconómicos aquí escogidos muestran diferencias muy importantes: Argentina registra un índice de analfabetismo mucho más bajo que Bolivia y Paraguay, y una proporción de población masculina económicamente activa en actividades no agropecuarias y un producto bruto interno por habitante mucho mayores.

Es pertinente ahora destacar las diferencias más notables entre Bolivia y Paraguay. Aun cuando por lo común se les clasifica como pobres, en niveles muy semejantes, difieren de manera fundamental en cuanto al fenómeno estudiado: la participación femenina en la actividad económica. En efecto, el caso boliviano es siempre destacado como de participación excepcionalmente alta para los niveles comunes en la región, de los que son dignos exponentes los casos argentino y paraguayo.

3 Véase, por ejemplo, CEPaI (1972). 


\section{Cuadro 1}

Argentina, Bolivia y Paraguay. Algunos indicadores demográficos Y SOCIOECONómICOS, 1947-1976

\begin{tabular}{|c|c|c|c|c|c|c|c|c|}
\hline \multirow{2}{*}{ Indicadores } & \multicolumn{3}{|c|}{ Argentina } & \multicolumn{2}{|c|}{ Bolivia } & \multicolumn{3}{|c|}{ Paraguay } \\
\hline & 1947 & 1960 & 1970 & 1.950 & 1975 & 1.950 & 1952 & 1972 \\
\hline Población total (en miles & 15894 & 20613 & 23748 & 3013 & 4688 & 1328 & $181:$ & 235.8 \\
\hline Tasa de crecimiento (por mil) & \multicolumn{3}{|c|}{19.6} & \multicolumn{2}{|c|}{21.4} & \multicolumn{3}{|c|}{$37.0 . \quad 30.0$} \\
\hline Población urbana $\left(\frac{\%}{0}\right)$ & 62 & 72 & 79 & 34 & 35 & 35 & 36 & 38 \\
\hline Densidad (hab/Km2.) & 5.7 & 7.4 & 8.6 & 2.8 & 4.9 & 3.3 & 4.5 & 5.8 \\
\hline Foblación $0-14 \quad\left(\frac{8}{0}\right)$ & 30.9 & 30.7 & 29.1 & 42.0 & 43.5 & 43.8 & 45.9 & 44.9 \\
\hline Tasa Elobal de fecundidad & 3.3 & 3.1 & 2.9 & $6.2^{\frac{a}{a}}$ & 6.8 & 6.1, 让 & - & $6.0 \mathrm{~b}$ \\
\hline $\begin{array}{l}\text { Tasa de mortalidad infantil. } \\
\text { (por mil nacidos wivos) }\end{array}$ & 72 & 60 & 60 & - & $101 \subseteq !$ & - & - & $64 \stackrel{d}{-}$ \\
\hline Esperanza de vida al nacer & 61.1 & 66.4 & 65.5 & 140.8 & 48.2 & 53.4 a & - & $61.6 \mathrm{~B} /$ \\
\hline Analfabetas 15 y mâs años $(\%)$ & $13.6-1$ & 3.6 & 7.4 & 67.9 & $29.2 \pm f$ & $34: 2$ & 25.4 & 19.9 \\
\hline $\begin{array}{l}\text { Poblacion masculina economica- } \\
\text { mente activa en actividades } \\
\text { no agropecuarias }(\%)\end{array}$ & 69.5 & 78.4 & 81.5 & 30.3 & & 35.1 & 35.8 & 40.5 \\
\hline $\begin{array}{l}\text { PBI por habitante (en dôlares } \\
\text { de } 1970 \text { ) }\end{array}$ & -. & 807.1 & 1050.3 & $1 E 1.8 \frac{g}{1}$ & $213.8^{\text {ht }}$ & - & $213.1^{8}$ & 271.6 \\
\hline
\end{tabular}

FuENTES: Argentina (s.f.a.), (s.f.b.) y (s.f.c.), Schkolnik (1975), Müller (s.f.), Rechini de Lattes y Lattes (1975), Bolivia (1955), (1975) y (1976), Behm, Hill y Soliz (1977), Somoza (1976), celade (1974), Corvalán y otros (1974), Paraguay (1962), (1966) y (1975), Behm y Brizuela de Ramírez (1977), Brizuela de Ramírez y Schoemaker (1978), BID (1973).

a Corresponde al periodo 1950-1955.

c Corresonde al periodo 1971-1972.

Corresponde al periodo 1971-1972.

e 14 y más años.

f Corresponde a datos de 1975.

g Corresponde a 1960.
h Corresponde a 1972. 
Bolivia y Paraguay, los únicos países mediterráneos de América del Sur, de población eminentemente rural, como ya se dijo, han crecido a tasas muy diferentes: moderada en Bolivia, elevada en Paraguay. Si bien ambas poblaciones no difieren mucho en sus niveles de fecundidad ( $\mathrm{y}$ por lo tanto sus proporciones de menores de 15 años son muy semejantes), sus niveles de mortalidad registran diferencias sustanciales. En efecto, a una vida media estimada en 61.6 años para el periodo 19701975 en Paraguay, corresponde una de 48.2 en Bolivia para 1976. Mientras en Paraguay de cada mil nacidos vivos en un año mueren 64, en Bolivia la cifra equivalente es 161. Este indicador serviría, por sí solo, para marcar las acentuadas diferencias en los niveles de vida de ambos países. Pero otros indicadores disponibles tienen el mismo sentido. $\mathrm{Si}$ bien ambos países han experimentado disminuciones muy sustanciales en el nivel de analfabetismo en el periodo estudiado, aún existe una amplia brecha entre los dos. Ambos difieren también en el PBI por habitante: si bien los dos países han mostrado mejoras considerables, en ambos sigue siendo muy bajo, pero el nivel de Bolivia en 1976 es equivalente al que exhibía Paraguay 14 años antes.

Para completar este breve panorama, deben destacarse las profundas diferencias en cuanto a los medios geográficos de ambos países y sus recursos naturales en relación con la distribución espacial de sus respectivas poblaciones.

Las distintas partes del territorio boliviano se distinguen, geográficamente, por su altura, que es el principal determinante climático, lo cual a su vez condiciona de manera importante los tipos de producción vegetal y animal posibles. En el altiplano, planicie cuya altura varía entre 3800 y 4800 metros sobre el nivel del mar, donde se encuentran los principales yacimientos minerales, se concentraba, en 1950 , el $58 \%$ de la población boliviana, la cual disminuyó al $52 \%$ en 1976 . Por lo demás, existe una agricultura de subsistencia que se llevaba a cabo con tecnología muy rudimentaria antes de la reforma agraria de 1953 y que en lo fundamental no parece haber cambiado desde entonces. Entre un 30 y un $28 \%$ de la población (respectivamente, en las dos fechas), vive en los valles interandinos semitropicales (yungas), con una altura comprendida entre los 1000 y los 3000 metros. La zona es propicia para el cultivo de gran variedad de productos vegetales que sin embargo no han prosperado grandemente. Hasta el decenio de los cincuentas, el único vegetal cultivado extensamente era la coca. Si bien la reforma agraria dio lugar a una distribución de tierras, al no ser suficientes las medidas previstas de protección a los pequeños y medianos propietarios, de promoción al cooperativismo, etc., ocasionó un minifundismo poco productivo. Por último, el resto del país, las tierras tropicales bajas, representa el 59\% del territorio. Por su clima tropical, estas tierras son potencialmente aptas para una agricultura extensiva y además poseen gran riqueza energética y petrolera. Zona privilegiada por la reforma agraria, ha visto multiplicar sus vías de comunicación, la promoción de una agricultura capitalista y 
la transformación de algunas de esas estructuras. Ha pasado a absorber el $19 \%$ de la población boliviana en 1976 (de un 12\% que tenía en 1950), en detrimento de las dos áreas restantes. En otras palabras, se ha iniciado, aunque de manera tímida, una redistribución de la población hacia las zonas potencialmente más ricas del país.

La geografía paraguaya no tiene, por el contrario, contrastes tan marcados, si bien pueden distinguirse climas desde el semiárido hasta el húmedo-mesotermal. Casi todo el territorio es potencialmente apto para la producción agrícola y, en las zonas que aún no han sido colonizadas, para la explotación forestal. La primera se efectúa todavía en su mayor parte con una tecnología muy rudimentaria y bajo el régimen minifundiario, si bien esta situación ha comenzado a cambiar en los últimos años.

La población está muy concentrada en la región Central: el $63 \%$ se localizaba en el 7\% de la superficie del país (incluida la capital, Asunción). Pero, a diferencia del altiplano boliviano - la zona que concentra mayormente la población boliviana- las condiciones geográficas son menos adversas para el establecimiento de medios de comunicación y para la producción agrícola. En el otro extremo, el Chaco, la zona principal de explotación de tanino, que representa casi el $61 \%$ de la superficie, estaba habitada por un $4 \%$ de la población en 1950 . Hasta 1972, se produce un proceso de redistribución de la población, en que pierde relativamente la región Central (que incluye a Asunción), y gana, sobre todo, Canendiyú (en los límites con Brasil).

\section{LOS DATOS: SU COMPARABILIDAD Y CALIDAD}

Como ya se dijo, esta investigación se basa en tres estudios de casos previos - correspondientes uno a cada país - que se efectuaron, a su vez, sobre la base exclusiva de datos secundarios. Se trata de los resultados de los tres últimos censos nacionales en los casos de Argentina $(1947,1960$ y 1970) y Paraguay $(1950,1962$ y 1972) y, en el caso de Bolivia, del antepenúltimo censo nacional $(1950)^{4}$ y de la Encuesta Demográfica Nacional de 1975.

Resulta clave para esta investigación comparativa la definición de población económicamente activa usada en cada una de las fuentes de información utilizadas. En los tres países se observa el mismo tipo de evolución de los conceptos adoptados a través del tiempo. En los tres casos, el concepto considerado en la primera fecha es el más impreciso, aunque si se tratara de establecer grados de imprecisión, Bolivia presentaría el más alto, ya que no define límite inferior de edades en la cédula censal, ni incluye el concepto de desocupado. En los tres casos, utilizan el viejo concepto de trabajador remunerado. En la segunda fecha censal,

4 En el momento de iniciar esta investigación no se había levantado el censo de población de 1976. 
tanto en Argentina como en Paraguay, se establecieron conceptos algo más precisos, mientras que en la última se han refinado todavía más, esta vez se utiliza el de fuerza de trabajo, con una semana de referencia en los tres casos, incluidos los desocupados y los jubilados o retirados de un empleo anterior que en la semana de referencia ejercían una actividad económica. Si bien no hay coincidencia en la edad límite inferior considerada para definir a la PEA (Población Económicamente Activa), ni a lo largo del tiempo en un mismo país - salvo el caso de Paraguaypara este análisis comparativo se resolvió esta dificultad al desechar a todos los menores de 15 años.

Así, aun cuando en apariencia no existirían graves problemas de comparabilidad para los tres países en fechas semejantes, resulta difícil determinar, en la práctica de la investigación, hasta dónde es comparable la información entre países para momentos determinados o para la determinación de tendencias. Las definiciones utilizadas, sobre todo las de fechas más recientes, aluden claramente al concepto de actividad económica para el mercado. Es claro que, en grados muy diversos en los tres países considerados, existen sectores de la población, sobre todo en sus áreas agropecuarias, que están bajo el régimen de economías de subsistencia. Es difícil decir en qué grado se incluyeron las actividades de subsistencia en los distintos relevamientos censales pero, como se verá más adelante, puede suponerse que se incluyeron en gran parte en Bolivia en 1950, no así en el mismo país en la encuesta de 1975 (o por lo menos no con el mismo grado de cobertura) ni en el caso de los distintos relevamientos censales de Argentina y Paraguay.

En cuanto a la clasificación de la PEA por ramas de actividad, ocupaciones y categoría ocupacional, se compatibilizaron los datos para hacerlos comparables a través del tiempo en cada uno de los casos y entre ellos. De esta manera resultaron agrupaciones más grandes que las disponibles para observaciones puntuales.

\section{La CURVA DE PARTICIPACIÓN TOTAL EN LOS TRES PAÍSES}

En los tres países se registran pautas de cambio totalmente diferentes en el lapso de los 22 a 25 años estudiados. Las medidas globales (años brutos de vida activa entre 15 y 69 años) muestran que, mientras en Bolivia las mujeres reducen de manera abrupta su participación entre 1950 y 1975, en Argentina se insinúa tímidamente un ascenso a partir de 1960 - luego de un descenso secular que se había iniciado a fines del siglo pasado- y en Paraguay se observa una oscilación sin cambios importantes ${ }^{5}$ (véanse el cuadro 2 y la gráfica 1 ). Cabe preguntarse, por

\footnotetext{
5 Brizuela de Ramírez y Schoemaker (1978) señalan que el descenso observado entre 1962 y 1972 es ficticio, ya que sería debido a, $a$ ) los diferentes periodos de referencia adoptados (un día en 1962 y una semana en 1972), pero sobre
} 
lo dicho en el punto anterior, si el descenso en Bolivia ha sido tan marcado eomo lo indican las cifras o si es más bien el resultado de cambios en la definición de PEA. No cabe duda que con el cuestionario utilizado en 1950 pueden haberse captado como activas a mujeres que no lo habrían sido con el de 1975. Por lo tanto, es probable que la magnitud del cambio esté exagerada. Sin embargo, se piensa que el sentido del cambio es real, dadas las transformaciones que se produjeron en el sistema de tenencia de la tierra y en la estructura social a partir de la reforma agraria de 1953. ${ }^{\circ}$

En cuanto a los niveles, como ya se dijo, Bolivia se separa de manera notoria de los otros dos casos, aún en la fecha más cercana, por sus valores más altos. Argentina y Paraguay presentan niveles globales más parecidos, aunque alrededor de 1970 comienzan a diferenciarse. Por otra parte, los tres países presentan situaciones político-sociales y procesos de desarrollo con diferencias muy claras, como se dijo antes. Así, se tratará de determinar si las similitudes y diferencias encontradas son tales cuando se empiezan a desagregar los niveles de análisis. En otras palabras, cada una de esas curvas globales ¿de qué agregados de curvas están compuestas? Encontrar la respuesta a esta pregunta permitirá avanzar en el conocimiento de la participación femenina en la actividad económica y su relación con el desarrollo económico, o al menos, con algunos de los procesos que tienen que ver con el desarrollo económico.

\section{LA PARTICIPACIÓN URBANA Y RURAL}

Un panorama totalmente diferente aparece cuando los niveles globales de actividad, medidos de nuevo por los años brutos de vida activa, son considerados por separado para las áreas urbanas y rurales de cada uno de los tres países. En primer lugar, debe señalarse que el sentido del diferencial rural-urbano no es el mismo en cada uno de los casos (véanse el cuadro 2 y la gráfica 1 ). Mientras Argentina y Paraguay presentan el

todo a; $b$ ) las variaciones estacionales en el tamaño de la PEA, ya que los censos de 1950 y 1962 fueron levantados en épocas de intensificación de las tareas agrícolas (octubre) y el de 1972 cuando se produce un relativo receso (julio). (En 1950 la PEA femenina en la agricultura constituye cerca de la cuarta parte del total de las mujeres activas).

6 En efecto, desde el momento en que se habilitó la reforma agraria hasta 1975 cambiaron las relaciones sociales de una buena cantidad de campesinos. Los campesinos que obtuvieron los títulos de propiedad de la tierra que trabajaban pasaron a ser dueños de sus propios jornales de trabajo, en lugar de entregar gratuitamente al patrón entre tres y cinco jornales semanales. (Para mayor información puede verse el artículo de Albó, 1976). De esta manera, es muy probable que se haya liberado parte de la mano de obra femenina e infantil, absolutamente necesarias para la propia subsistencia antes de que esos cambios tuvieran lugar. Cambios que hicieron predecir a Fucaraccio (1974) el descenso que se produciría en la participación femenina antes de que hubiera información disponible para probarlo. 


\section{Cuadro 2}

Argentina, Bolivia y Paraguay. Número bruto de años de vida aCtiva de la POBLACIÓN FEMENINA ALREDEDOR DE LOS AÑOS 1950, 1960 Y 1970, ${ }^{\text {a }}$ SEGÚN ÁREA URBANA Y RURAL

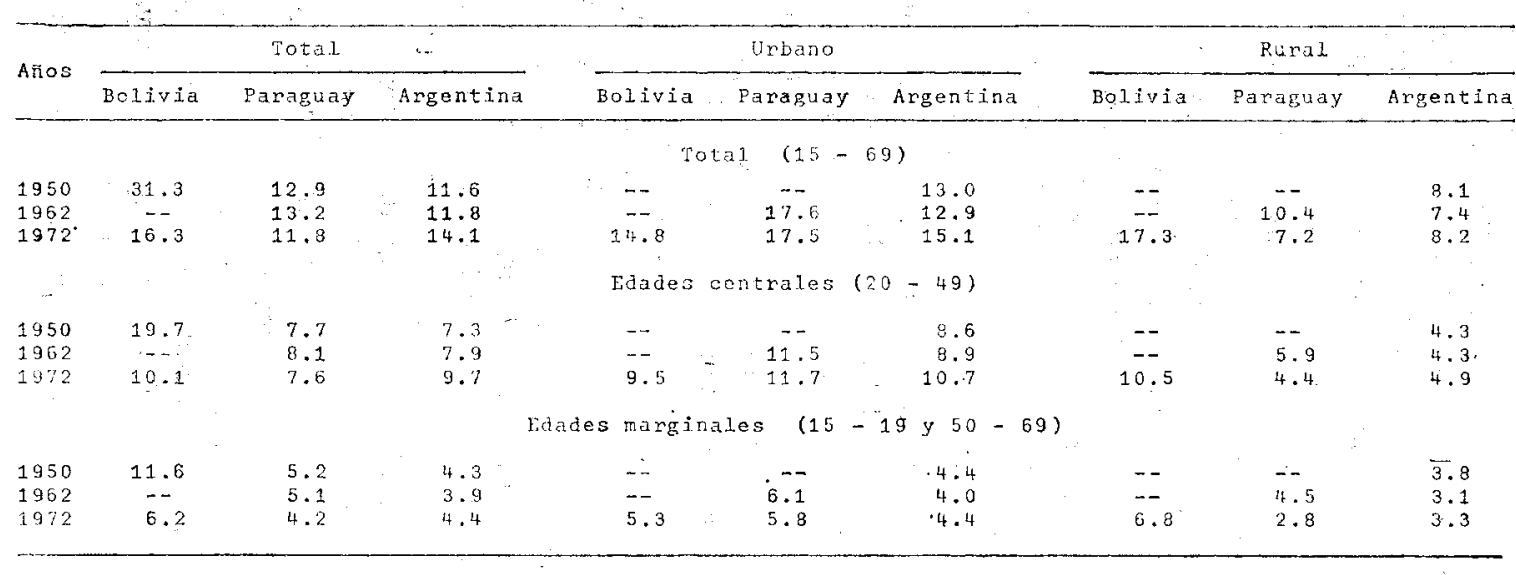

Fuentes: Argentina: Recchini de Lates (1977), cuadros1.2 y B.1.; Recchini de Lates (1975), cuadro 6.2. Bolivia: Torrez (1977), cuadro 12 y Bolivia (1975), cuadros 01 y 06; Bolivia (1955), cuadros 9 y 47.

Paraguay: Brizuela de Ramírez y Schoemaker (1978), cuadro 6. 
diferencial típico latinoamericano, o sea, participación más elevada en las áreas urbanas que en las rurales, en Bolivia tiene el sentido inverso para 1975 (única fecha disponible). Si bien se podría aducir una vez más, como es común en la literatura, que puede haber problemas en la captación de los datos de las zonas rurales que los haga no comparables en los tres países, se cree más bien que en todos los casos los datos muestran en realidad el sentido del diferencial. Parece, efectivamente, ser una pauta común a la mayoría de los países latinoamericanos que las mujeres tengan muy baja participación en zonas rurales, ya sea porque las oportunidades son menores en esas zonas, porque la cultura "dice" que las mujeres no se ocupan de determinados tipos de tareas y, por lo tanto, las que de manera efectiva realizan no son percibidas como económicas ni por las propias mujeres que trabajan ni por el medio social circundante. ${ }^{7}$ De manera coherente con las pocas oportunidades económicas que las mujeres encontrarían en las zonas rurales, se observan movimientos migratorios importantes de las zonas rurales a las urbanas - los que en Paraguay adquirirían la forma de migración hacia áreas urbanas de la Argentina-, lo cual apoyaría la hipótesis de mayores oportunidades de trabajo remunerado en las zonas urbanas. En Bolivia, la explicación del sentido del diferencial hay que buscarla en la situación socioeconómica del campesinado y en el medio físico tan desfavorable para la producción agrícola de la parte del territorio donde está ubicada la mayor parte de la población del país: el altiplano. La conjunción de estos factores con la tecnología en extremo primitiva utilizada es lo que hace decir a Fucaraccio (1974) al referirse a la situación anterior a la reforma agraria de 1953, que es necesaria "una utilización intensiva del esfuerzo humano como medio de obtención de los productos necesarios para la subsistencia" (p. 10). La reforma agraria modificó, pero sólo de manera parcial, esta situación. En primer lugar, si bien la misma alcanzó a un número importante de campesinos, dista bastante de haberlos abarcado universalmente. En segundo lugar, la distribución de tierras no fue acompañada, en general, por medidas de asistencia técnica y cooperativización. Por lo tanto, no se han modificado de manera esencial los medios de trabajo utilizados e impera un minifundio que aun requiere una mano de obra intensiva que debe obligar - más que en otras regiones de América Latina- a trabajar a una mayor proporción de mujeres. Es también probable que siga actuando la tradición cultural de una elevada participación femenina en las tareas agrícolas cuyas raíces haya que buscar, probablemente, en la economía agrícola de los incas.

En cuanto a la tendencia a la participación urbana y rural -que no

; Como por ejemplo en el área pampeana argentina, donde, además de ser la zona más poblada del país, de ganadería, agricultura y mano de obra poco intensiva, las tareas que se realizan para el mercado son efectuadas casi en exclusiva por hombres. 


\section{Gráfica 1}

Argentina, Bolivia y Paraguay: AÑos brutos de vida activa (abVa) DE LA POBLACIÓN FEMENINA, SEGÚN GRUPOS DE EDADES Y ZONA URBANA 9 RURAL

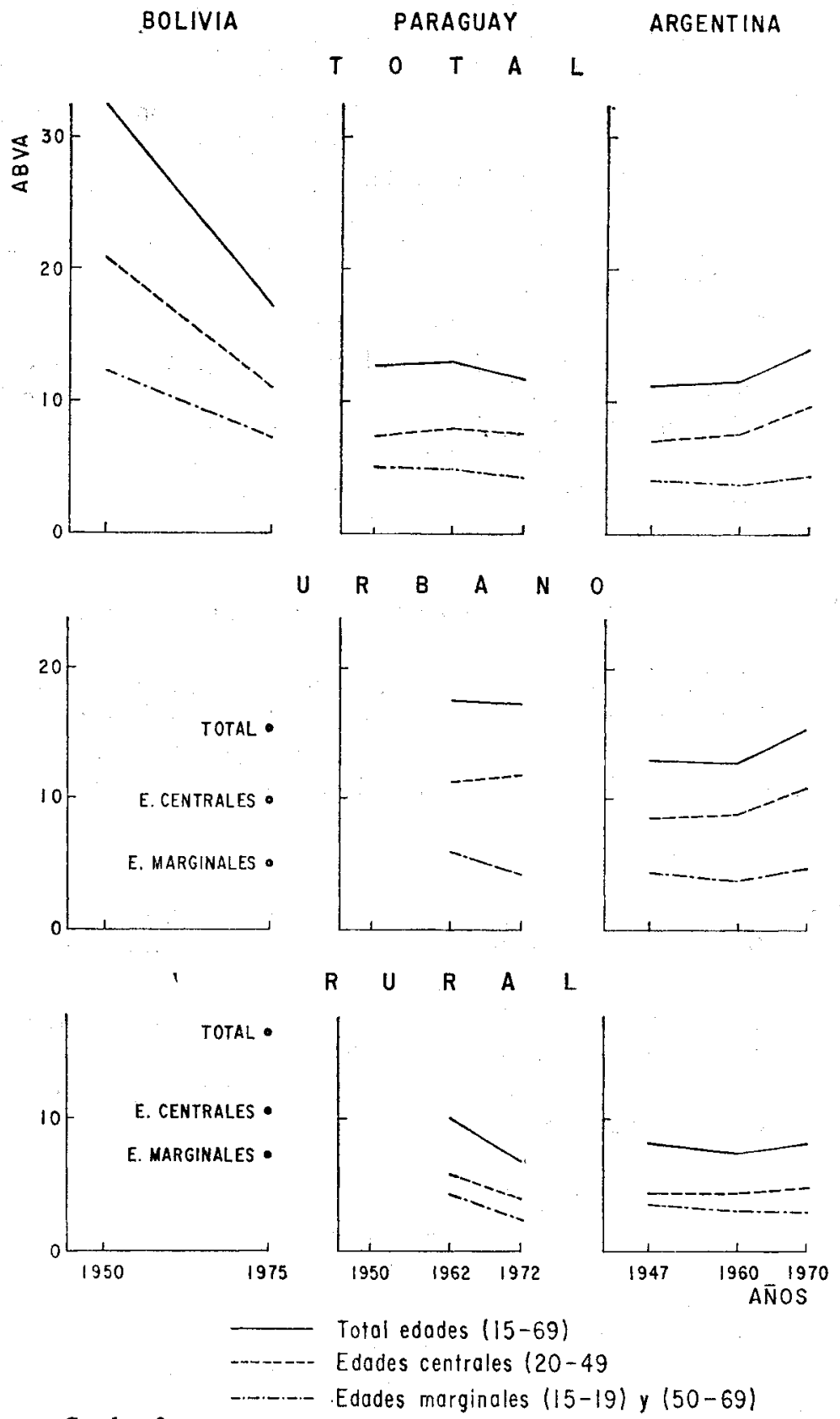

Fuente: Cuadro 2. 
puede ser observada para Bolivia, país para el cual se dispone de datos de un solo momento- en Argentina, el cambio en la participación urbana global, como era de esperarse, no hace sino repetir la del total del país, dado que la población urbana constituye amplia mayoría en el país durante el periodo estudiado. En Paraguay, con datos para las dos últimas fechas, la invariabilidad del valor correspondiente a la zona urbana total refuerza la afirmación anterior, en el sentido del estancamiento de la situación paraguaya en lo que hace a la participación femenina. El descenso en el nivel de la participación rural podría señalar la diferente intensificación de tareas agrícolas en diferentes épocas del año, así como también una disminución real.

Por último, en cuanto a participación urbana se refiere, se altera del todo el rango que ocupan los países entre sí. Paraguay resulta con la participación más alta, seguido de Argentina con un valor casi coincidente al de Bolivia (véase la gráfica 1). Las razones de este ordenamiento aparecerán más claras en los próximos apartados, cuando se desagreguen los niveles de participación de acuerdo a otras variables.

\section{La PARTICIPACIÓN EN LOS DISTINTOS TRAMOS DEL CICLo VITAL}

Dado que el objetivo principal de este análisis son los cambios, o mejor dicho, la desagregación de los cambios observados a nivel global y que, como se dijo antes, pueden esperarse tendencias muy diferentes en distintos tramos del ciclo vital, se los analizará por separado.

\section{Las edades centrales}

Se denominan edades "centrales" en este artículo a las comprendidas entre los 20 y los 49 años de edad. Las tendencias observadas en el conjunto de estas edades para los tres países, repiten, a grandes rasgos, lo observado para el total de las mujeres (véase la gráfica 1): un descenso muy pronunciado en Bolivia; una tendencia creciente que comienza, aunque muy leve, en 1947 y es más marcada entre 1960 y 1970 en Argentina y; una permanencia de valores en Paraguay, con un ligero aumento en la fecha intermedia.

En la Argentina, la curva del total del país se repite, a un nivel más elevado, en la región urbana, no así en la rural. En Paraguay, por el contrario, el sentido del cambio observado en el total del país se repite de modo más acentuado en la zona rural (descenso), no así en la urbana que se mantiene prácticamente constante.

Otra manera de ver los cambios es a través de las variaciones experimentadas por las cohortes a lo largo de su ciclo vital, lo que sólo podrá 
hacerse para los casos de Argentina y Paraguay, debido a la escasez de datos para Bolivia. ${ }^{8}$

Gráfica 2

Argentina: Tasas de participación (TP) DE MUJeRes de 20 a 54 años SEGÚN COHORTES DE NACIMIENTO, 1945-1970

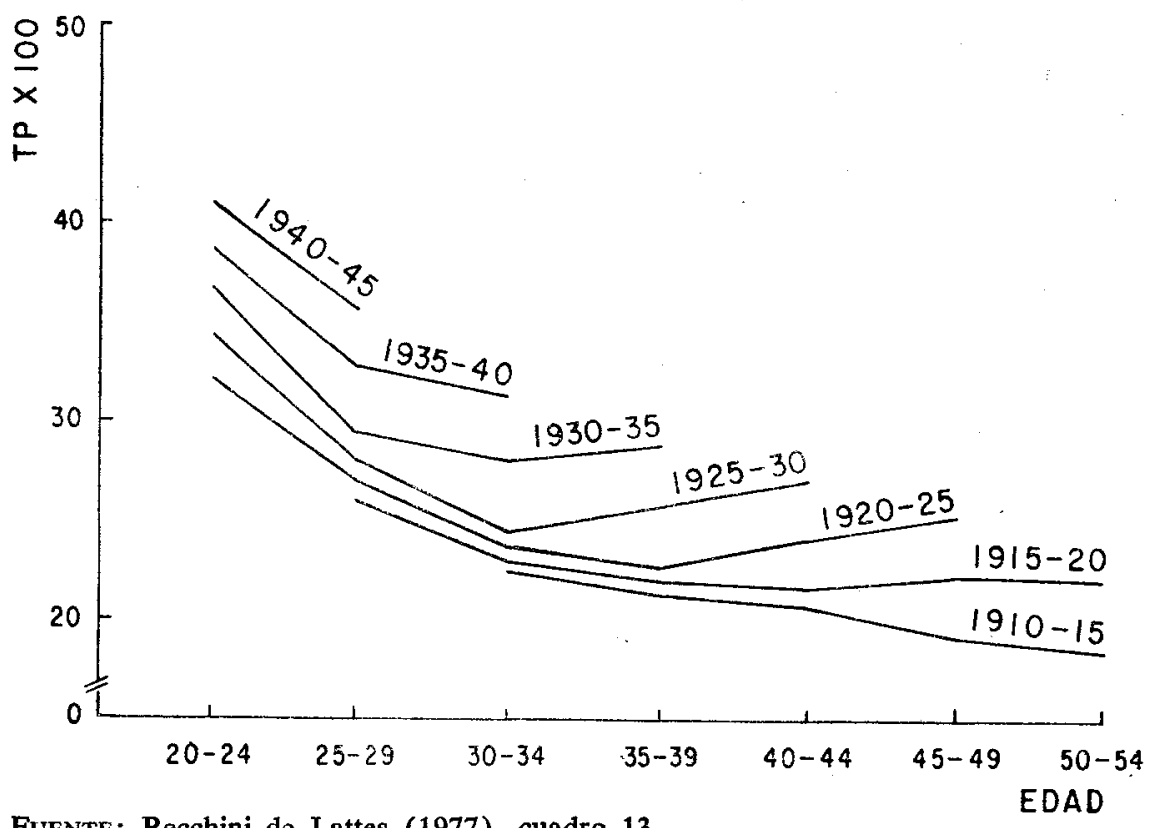

FUENTE: Recchini de Lattes (1977), cuadro 13.

Las diferencias anotadas entre Argentina y Paraguay en el análisis precedente, se hacen aún más evidentes al comparar el comportamiento de las cohortes respectivas. Las cohortes argentinas siguen pautas de cambio muy claras, tal como muestra la gráfica 2 . La variación observada puede sintetizarse de la siguiente manera: las cohortes más jóvenes participan más que las de edades más avanzadas a lo largo de todos los tramos observados del ciclo vital. Este aumento se ha llevado a cabo de diversa manera en las distintas cohortes (observadas, por otra parte, en tramos sólo en parte coincidentes de sus ciclos vitales). Por una parte, en los tramos jóvenes, las cohortes más jóvenes llegan a las edades activas con propensiones más elevadas a participar y alcanzan el máximo -a los 20-24 años-con tasas más elevadas que las registradas para las cohortes más viejas a edades similares. Luego del máximo mencionado, todas las

8 Para que el "seguimiento" de las cohortes a lo largo de su ciclo vital tenga sentido, los datos no deben estar muy espaciados, lo conveniente sería por no más de diez años. Los datos de Bolivia están separados por 25 años, por lo que su análisis no resulta fructífero, motivo por el cual se lo desecha. 
Gráfica 3

Paraguay: Tasas de participación de mujeres de 20 a 54 años SEGÚN COHORTES DE NACIMIENTO, 1952-1962 Y 1962-1972

Periodo $1952-62$

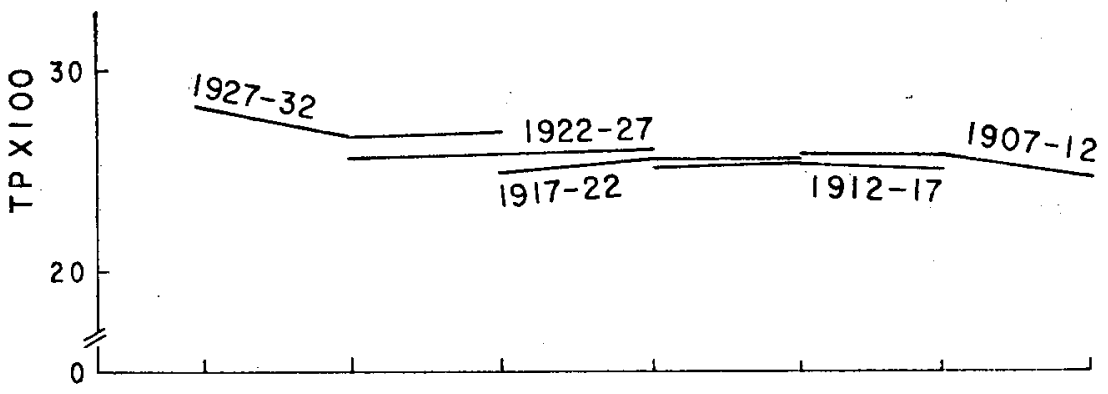

Periodo $1962-72$

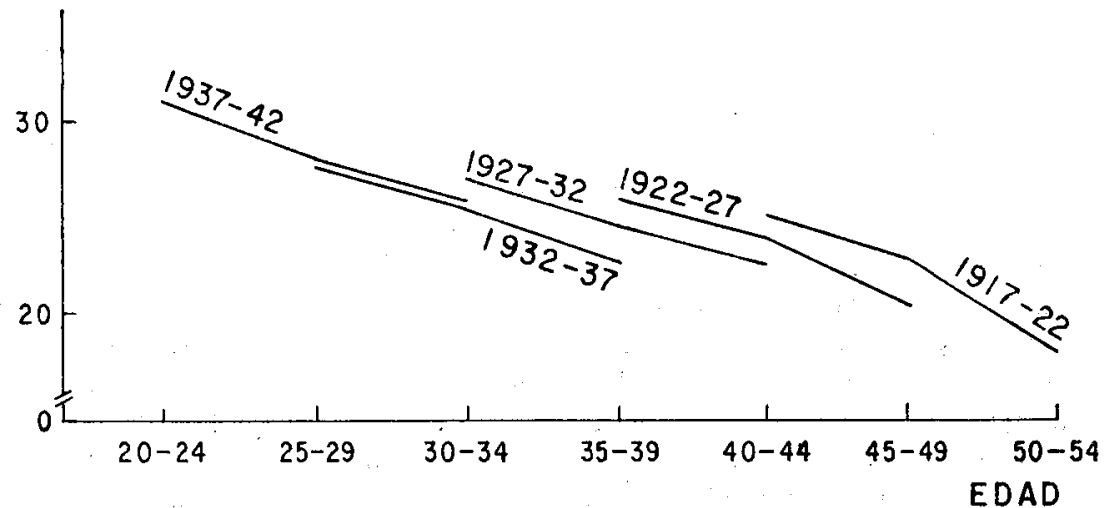

Fuente: Brizuela de Ramírez y Schoemaker (1978), cuadro 10.

cohortes reducen sus tasas de participación, pero en las más jóvenes el descenso es menos pronunciado. Por último, cuando las cohortes transitan edades entre 30-34 y 45-49 años, se producen cambios muy drásticos entre el comportamiento de las cohortes más viejas y las más jóvenes. Mientras aquéllas reducen sin interrupción su participación a medida que avanzan en edad, en las últimas se produce un aumento muy importante que ocurre, en el tiempo, entre 1960 y 1970 y que probablemente sea la primera vez que se da en la historia del país. Cambios sociales muy im- 
portantes han ocurrido sin lugar a dudas en el último decenio, los cuales se ven reflejados en una nueva entrada a la actividad económica de mujeres que antes habían estado en el mercado de trabajo y habían salido, o de mujeres que entraron por primera vez al mismo a edades maduras.

Por otra parte, el caso paraguayo presenta un panorama totalmente diferente. El análisis de Brizuela de Ramírez y Schoemaker (1978) mostraba que, si bien a las edades de entrada en la actividad las cohortes jóvenes lo hacen de manera sistemática con tasas más elevadas que las más antiguas, en tramos avanzados del ciclo vital sucedía exactamente lo contrario. Es que el comportamiento observado parece ser más bien el reflejo de defectos en los datos básicos que de los sucesos ocurridos en la realidad, como surgirá del análisis que se hace a continuación.

Para facilitar el análisis, en la gráfica 3 se han separado las trayectorias seguidas por las cohortes en cada uno de los dos decenios observados: 1952-1962 y 1962-1972. En el primero, sólo se observan cambios en el comportamiento de las cohortes más jóvenes, observables en tramos jóvenes (hasta los 35-39 años): las cohortes más jóvenes participan más que las más viejas. En los tramos más avanzados (cohortes más viejas), prácticamente no se observan cambios.

En el segundo decenio, por el contrario, el panorama es del todo diferente: en todas las cohortes observadas, las más viejas participan más que las más jóvenes. Si descomponemos en este periodo las cohortes en urbanas y rurales (ya que los datos disponibles así lo permiten) podemos observar (véase la gráfica 4) que: a) en las cohortes rurales el comportamiento observado se corresponde de manera plena con el descrito para la población total, aunque con diferencias todavía más marcadas; $b$ ) en las cohortes urbanas, por el contrario, las diferencias entre cohortes más jóvenes y más viejas son exactamente opuestas y similares, por lo tanto, a las observadas en el total del país en el decenio anterior: las cohortes más jóvenes presentan propensiones más altas que las más viejas al transitar por tramos equivalentes del ciclo vital.

Otra diferencia entre las cohortes argentinas y las paraguayas -observadas en los dos decenios- es que las primeras, al transitar entre los 20-24 y los 25-29 o los 30-34 años, disminuyen de manera muy rápida su participación, mientras que las segundas lo hacen mucho más lentamente (compárense las gráficas 2 y 3 ). Ya que las mujeres paraguayas tienen una fecundidad más elevada que las argentinas, es difícil pensar que su disminución más lenta en la participación se deba a un retardamiento importante en la edad al tener los hijos o, más drásticamente, a una mayor fecundidad. Más bien debe tener relación con el tipo de ocupaciones predominantes en cada sociedad. Es posible que en Paraguay sea más fácil combinar el rol económico con el doméstico, porque en gran parte ambos pueden ser realizados dentro del ámbito familiar.

Este análisis lleva a concluir que, de ser confiables los datos de 1972 del área urbana, se observarían en Paraguay, a lo largo de los dos decenios, cambios - aunque no muy pronunciados - ascendentes. O sea 


\section{Gráfica 4}

Paraguay: Tasas de participación de mujeres de 20 a 54 años SEGÚN COHORTES DE NACIMIENTO Y RESIDENCIA URBANA O RURAL, 1962-1972

\section{URBANAS}

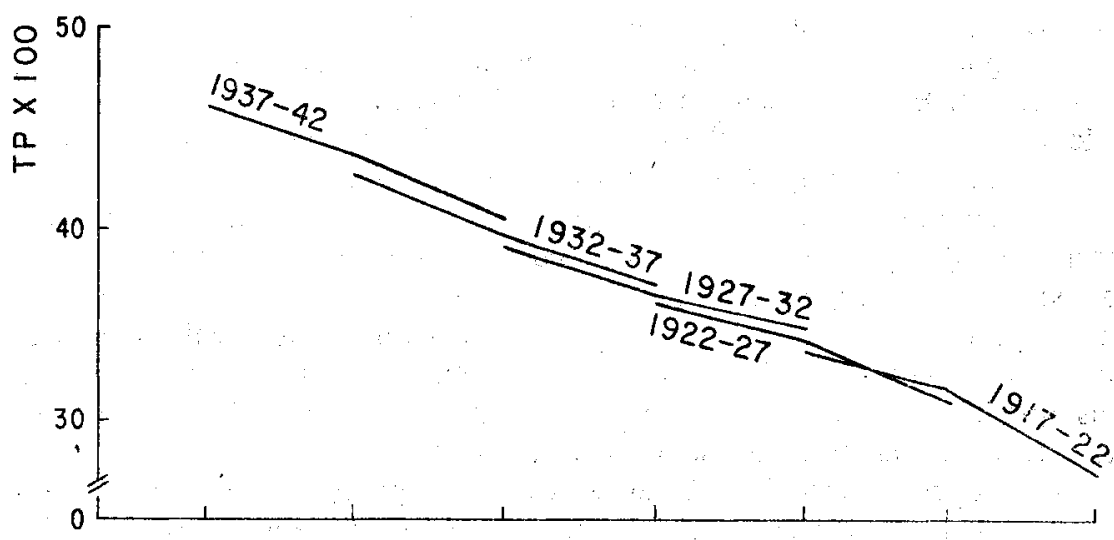

RURALES

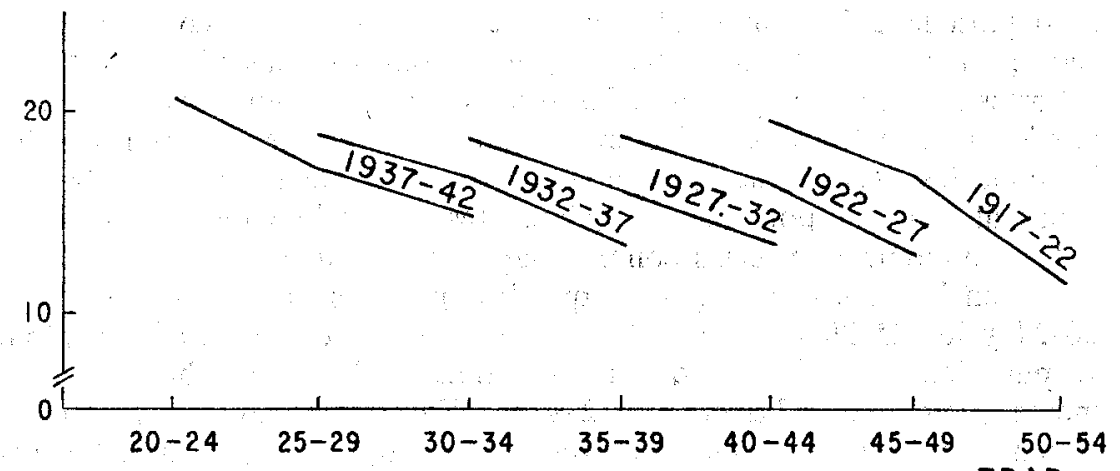
EDAD

Fuente: Calculados en datos elaborados por Brizuela de Ramérez y Schoemaker (1978), cuadro 6 .

que de estos datos parciales podría concluirse que, ya que es más confiable predecir a partir del comportamiento de las cohortes, es probable que en el Paraguay urbano en los próximos años siga aumentando, aunque en forma más lenta que en la Argentina, la participación femenina. En cuanto al área rural, donde los datos parecen ser menos confiables, como 
ya se dijo y no puede determinarse cuánto corresponde a una disminución real y cuánto a problemas de la información básica, resulta muy riesgosa la predicción de una disminución para los próximos años, que es lo que permitiría predecir la lectura de la gráfica 4 .

\section{Las primeras y las últimas etapas del ciclo vital activo}

Estas etapas, denominadas aquí en forma sintética edades "marginales" engloban a las mujeres de 15 a 19 años, por una parte y a las de 50 a 69 por otra.

Como puede verse en el cuadro 2 y la gráfica 1 , en los casos analizados es clara la tendencia de los años brutos de vida activa a disminuir en Bolivia y Paraguay: ésta es la tendencia efectivamente esperada para ambos sexos cuando se dan mejoras sociales, aunque sean pequeñas. La tendencia en Argentina es, en cambio, oscilante: disminuyen entre 1947 y 1960 y aumentan entre esta última fecha y 1970, tanto en el total como en las zonas urbana y rural (véase, asimismo, la gráfica 1). Hay que analizar los datos más en profundidad en este último caso para entender lo de la tendencia oscilante. Esta se debe al comportamiento observado en las mujeres entre 50 y 64 años, que redujeron su actividad y luego la aumentaron de manera notable. En primer lugar, las tasas de 1960 pueden aparecer demasiado reducidas por defecto de la información censal, como ya se dijo en un informe anterior (Recchini de Lattes, 1977), pero las de 1970 son más elevadas que las de 1947; en segundo término, se piensa que actuaron las ya mencionadas fuerzas contrapuestas, o sea, que se retiraron de la actividad un buen número de mujeres que estaban en condiciones de acogerse a las leyes de retiro y, por otra parte, otra cantidad de mujeres, aunque de edades más bien avanzadas, estaban siguiendo esa "onda" generalizada de aumento en la participación en la actividad económica. Se debe tener presente, además, que para poder acogerse a las leyes de retiro hay que contar con un número mínimo de años de participación en la actividad (además de una edad mínima). Por lo tanto, las mujeres que entraron a la fuerza de trabajo en una etapa relativamente avanzada del ciclo vital deberán permanecer en ella hasta edades más altas que sus congéneres que empezaron su vida activa en edades más tempranas.

Aunque en el Paraguay urbano el cambio es nuevamente pequeño, debe observarse, sin embargo, que es de sentido contrapuesto al observado para las edades centrales: mientras en aquéllas aumentaba ligeramente, en éstas disminuye. Ya que la disminución no se produce entre las jóvenes de 15-19 años — que se comportaron en forma similar a las de edades centrales - sino entre las de edades avanzadas (Brizuela de Ramírez y Schoemaker, 1978), cabe preguntarse si ha tenido lugar una modificación en los sistemas de retiro que explique este hecho. En el Paraguay rural, el cambio es coincidente con el observado en las edadés centrales, o sea, de franca disminución. De esta manera se observa que 
la curva rural global es un agregado de curvas similares para los dos grupos de edades considerados. Por el contrario, la curva urbana global es el producto de dos tendencias contrapuestas: aumento en las edades centrales y disminución en las marginales.

En resumen, la desagregación de la curva total en edades centrales y marginales ha mostrado que son sobre todo las primeras las que rigen la forma del total. Por el contrario, las edades marginales muestran tendencias menos marcadas. Asimismo, se ha visto que los tres casos se ubican en un orden diferente en cuanto a la magnitud de su participación si se analiza la participación urbana por una parte y la rural por la otra y que ambas pueden mostrar también tendencias diferentes.

\section{VII. ¿DEMANDA, AUTOEMPleo o ECONOMía DE SUBSISTENCIA?}

El análisis de la demanda de la fuerza de trabajo no es posible hacerlo con los datos estadísticos disponibles. Simplemente se supone que si las mujeres están activas en ciertas ramas u ocupaciones es que ha existido una demanda que, en ciertos casos ha sido llenada por mujeres, por implicar actividades si no típicas, al menos relativamente "femeninas". ${ }^{9}$ Claro que este supuesto, aceptado muchas veces como cierto para otro tipo de economías en las que predominan los sectores de mercado y las actividades gubernamentales (véase, por ejemplo, Oppenheimer, 1970) puede no ser aceptable en sociedades donde el sector de subsistencia es importante o hay una alta proporción de autoempleo, o ambas cosas. En el sector de subsistencia no existe una demanda propiamente dicha, sino que "el individuo se integra en la división social del trabajo como consecuencia directa del hecho de ser miembro de la sociedad" (Singer, 1975, p. 1). La existencia de autoempleo estaría señalando un exceso de oferta de mano de obra que no es absorbida por los sectores hegemónicos de la economía, o sea, es mano de obra que crea su propia demanda debido a la inexistencia de oportunidades de empleo asalariado. Así, en este tipo de sociedades la estructura de la mano de obra por ramas de actividad o por grupos ocupacionales no reflejaría la demanda propiamente dicha, sino la estructura de la economía (con su parte o no de subsistencia y su existencia o no de subempleo), la organización social del trabajo y la inserción de las mujeres en ella. Aquí se analiza cómo ha variado a través del tiempo en los casos estudiados la inserción femenina en la estructura económica de cada país y en función de estos cambios se interpretarán los cambios en la participación total. En otras palabras, veremos de qué desagregado de curvas están compuestas las curvas

- La definición de tarea "femenina" por supuesto puede variar de una sociedad a otra. En general, las ocupaciones femeninas están ligadas a definiciones culturales o tradicionales de lo que son trabajos femeninos; tienen que ver con el adiestramiento previo; las motivaciones para buscar empleo, son en general las relativamente peor retribuidas, etc. 
de actividad total en términos de la estructura y el modo de organización de cada economía a través del tiempo. Por supuesto, los datos disponibles -en general con agrupaciones poco detalladas- limitan las posibilidades de análisis, pero reflejarán, de alguna manera, las distintas situaciones encontradas.

La desagregación muestra, de nuevo, diferencias aún más marcadas que en los puntos anteriores. Al comienzo del periodo abarcado por esta investigación (único punto para el cual se disponía de datos para los tres casos), los resultados son claros, ya sea que se desagregue por ramas de actividad, por ocupaciones o por categoría ocupacional. De manera coherente con lo encontrado cuando se desagregó la información en urbanorural, Bolivia registra tasas refinadas de participación en el sector agropecuario o, si se usa la clasificación ocupacional, en ocupaciones agrícolas que son, aproximadamente, ocho veces las de Paraguay y alrededor de treinta veces las de Argentina (véanse los cuadros 3 y 4). Por el contrario, la tasa refinada de participación en sectores no agrícolas era, en 1950, la más baja de los tres países estudiados. Estas tasas femeninas no

\section{Cuadro 3}

\section{Argentina, Bolivia y Paraguay. Tasas de participación DE LA POBLACIÓN FEMENINA DE 15 Y MÁs AÑOS SEGÚN GRUPOS DE OCUPACIÓN ${ }^{a}$}

(Fechas disponibles, 1947-1972)

\begin{tabular}{|c|c|c|c|c|c|c|c|}
\hline \multirow{2}{*}{ Grupos de ocupación } & \multicolumn{3}{|c|}{ Argentina } & \multirow{2}{*}{$\frac{\text { Bolivia }}{1950}$} & \multicolumn{3}{|c|}{ Paraguay } \\
\hline & 1947 & 1960 & 1970 & & 1950 & 1962 & 1972 \\
\hline Total & $23.5^{\circ}$ & 23.4 & 26.5 & 60.0 & .22 .7 & $\underline{22.9}$ & $\underline{21.1}$ \\
\hline $\begin{array}{l}\text { Agricultoras y afines } \\
\text { Total no agricultoras } \\
\text { oficinistas b/ } \\
\text { Servicio doméstico } \\
\text { Artesanas c/ } \\
\text { Resto }\end{array}$ & $\begin{array}{r}1.4 \\
22.1 \\
5.3 \\
7.2 \\
6.7 \\
2.9\end{array}$ & $\begin{array}{r}1.1 \\
22.3 \\
7.2 \\
4.8 \\
5.1 \\
5.2\end{array}$ & $\begin{array}{r}0.9 \\
25.6 \\
8.7 \\
6.1 \\
4.5 \\
6.3\end{array}$ & $\begin{array}{r}45.3 \\
14.7 \\
2.2 \\
5.1 \\
4.0 \\
3.4\end{array}$ & $\begin{array}{r}5.3 \\
17.4 \\
2.0 \\
4.9 \\
6.9 \\
3.6\end{array}$ & $\begin{array}{r}4.9 \\
18.0 \\
2.9 \\
3.8 \\
7.6 \\
3.6\end{array}$ & $\begin{array}{r}2.7 \\
18 \cdot 4 \\
3 \cdot 2 \\
5.3 \\
5.7 \\
4.2\end{array}$ \\
\hline
\end{tabular}

a Las tasas se calcularon como el cociente entre mujeres activas de 15 años y más en cada grupo ocupacional y el total de mujeres de las mismas edades.

b Incluye profesionales, técnicos y trabajadores afines; gerentes, administradores y funcionarias de categorías directivas; empleadas de oficina y personas en ocupaciones afines.

c Incluye artesanas y operarias en ocupaciones relacionadas con la hilandería, etc.; otras artesanas y operarias y obreras y jornaleras no especificadas en otras ocupaciones, según la clasificación de cota 1960. Contiene, además, las vendedoras ambulantes para Argentina, las que están incluidas en "Resto" en Paraguay ỳ en Bolivia.

FUENTES: Argentina: Recchini de Lattes (1977), cuadros 1.1 y 2.7.

Bolivia: Torrez (1977), cuadros complementarios; Bolivia (s.f.), cuadro 69.

Paraguay: Brizuela de Ramírez y Schoemaker (1978), cuadros 2 y 4; CELADE (s.f.) y Paraguay (1962), cuadro 22. 
Cuadro 4

Argentina, Bolivia y Paraguay. Tasas de participación DE LA POBLACIÓN FEMENINA DE 15 AÑOS Y MÁS SEGÚN SECTORES DE ACTIVIDAD ${ }^{\mathrm{a}}$

(Fechas disponibles, 1947-1972)

\begin{tabular}{|c|c|c|c|c|c|c|c|}
\hline \multirow{2}{*}{ Sectores de actividad } & \multicolumn{3}{|c|}{ Argentina } & \multirow{2}{*}{$\frac{\text { Bolivia }}{1950}$} & \multicolumn{3}{|c|}{ Paraguay } \\
\hline & 1947 & 1960 & 1970 & & 1950 & 1962 & 1972 \\
\hline Tota1 & 23.5 & 23.4 & 26.5 & 00.0 & 24.3 & 24.8 & 22.9 \\
\hline \multicolumn{7}{|l|}{ Agricultura, silvicultura } & 3.0 \\
\hline Total no agropecuario & $21: 8$ & 22.3 & 25.5 & 14.5 & 18.5 & 19.3 & 19.9 \\
\hline Industria manufacturera & 7.7 & 5.5 & 4.8 & $-\frac{1.7}{4.7}$ & 7.2 & 7.4 & 6.3 \\
\hline Comercio & 2.0 & 2.4 & 3.8 & 2.5 & 2.9 & 3.1 & 3.5 \\
\hline Servicios & 11.4 & 11.6 & 13.9 & 6.5 & 8.3 & 8.3 & 9.1 \\
\hline Resto y desconocido & 0.7 & 2.8 & 3.0 & 0.8 & 0.1 & 0.5 & 1.0 \\
\hline
\end{tabular}

a Cálculo similar al explicado en la nota a del cuadro 3 .

FUENTES: Argentina: Recchini de Lattes (1977), cuadro 2.3. y cuadros del Apéndice $B$.

Bolivia: Torrez (1977), cuadros complementarios.

Paraguay: Brizuela de Ramírez y Schoemaker (1978), cuadros 2 y 3.

hacen sino reflejar la estructura sectorial del empleo total en los tres países. En efecto, aunque los principales productos exportables de Bolivia son los de la minería, dan ocupación a una muy pequeña cantidad de trabajadores. Por el contrario, el $72 \%$ de la PEA total en 1950 estaba en el sector agropecuario -en economías de subsistencia, en gran parte. Las proporciones correspondientes eran $55 \%$ en Paraguay y $26 \%$ en Argentina. Además, por el tipo de explotación, en Bolivia se encuentra que la tasa de participación de las trabajadoras familiares no remuneradas era casi el $41 \%$ de la población de 15 y más años, mientras que 1a tasa equivalente para Argentina era casi despreciable en 1960 y muy reducida en Paraguay en $1962^{10}$ (véase el cuadro 5).

En cuanto a la participación en servicio doméstico, en Argentina es, de manera notoria, más elevada que en Paraguay y, sobre todo, que en Bolivia. En efecto, como diversas investigaciones lo han mostrado (por "ejemplo, Jelin, 1977; Youssef, 1974), es en especial en América Latina urbana donde el servicio doméstico es numéricamente importante. Esto es así porque, por una parte, las mujeres migrantes a las grandes ciudades constituyen una oferta considerable $y$, por la otra, porque existiría una demanda constante, potencialmente siempre insatisfecha - como dice Arizpe (1976), "el servicio doméstico funciona como un seguro económico para las mujeres pobres, migrantes, y de la misma ciudad: siempre

10 No existen datos para Paraguay de 1950 y los datos argentinos correspondientes a 1947 no son fidedignos. 
hay trabajo en él" (p. 638). En Argentina, un país con gran proporción de población urbana y un porciento apreciable de población de clase media y alta, el servicio doméstico probablemente sea más demandado que en Bolivia y Paraguay, ambos con mayoría abrumadora de población rural y pirámides sociales con bases más anchas que la de Argentina. Por otra parte, es probable que en esta última, todavía no estuviesen dadas - ni estén - las condiciones para que esas mujeres que necesitan de un trabajo remunerado puedan emplearse en otras ocupaciones mejor remuneradas o mejor consideradas socialmente (que no implican relaciones serviles), como operarias en fábricas, vendedoras en tiendas, otros tipos de servicios personales, etc., ya sea porque la demanda en esas ocupaciones no es lo suficiente alta o porque esas ocupaciones implican en general menos flexibilidad que la de empleada doméstica en cuanto a horario y posibilidad de combinar la tarea remunerada con la del cuidado de los hijos, por lo cual algunas mujeres pudieran seguir prefiriéndolas.

\section{Cuadro 5}

\section{Argentina, Bolivia y Paraguay. Tasas de participación DE LA POBLACIÓN FEMENINA DE 15 AÑos Y MÁs SEGÚN CATEGORÍA OCUPACIONAL ${ }^{a}$}

(Fechas disponibles, 1950-1972)

\begin{tabular}{|c|c|c|c|c|c|}
\hline \multirow{2}{*}{ Categoría ocupacional } & \multicolumn{2}{|c|}{ Argentina } & \multirow{2}{*}{$\frac{\text { Bolivia }}{1950}$} & \multicolumn{2}{|c|}{ Paraglay } \\
\hline & 1960 & 1970 & & 1962 & 1972 \\
\hline Potal & 23.4 & 26.5 & 60.0 & 24.8 & 22.9 \\
\hline $\begin{array}{l}\text { Asalariadas } \\
\text { Fatronas } \\
\text { Cuenta propia } \\
\text { Faniliares no remuneradas } \\
\text { Desconocido. }\end{array}$ & $\begin{array}{r}18.5 \\
1.0 \\
2.5 \\
0.6 \\
0.8\end{array}$ & $\begin{array}{r}20.14 \\
0.5 \\
3.2 \\
0.9 \\
1.5\end{array}$ & $\begin{array}{r}9.2 \\
0.4 \\
5.1 \\
40.7 \\
4.6 \mathrm{E} /\end{array}$ & $\begin{array}{r}10.3 \\
0.2 \\
11.1 \\
2.8 \\
0.2\end{array}$ & $\begin{array}{l}11.9 \\
0.8 \\
8.5 \\
1.9 \\
0.3\end{array}$ \\
\hline
\end{tabular}

a Cálculo similar al explicado en la nota a del cuadro 3.

b Incluye las categorías siguientes: colono, comunarios y otros.

FUENTES: Argentina: Recchini de Lattes (1977), cuadros 1.1 y 2.6

Bolivia: Torrez (1977), cuadros complementarios.
Paraguay: Brizuela de Ramírez y Schoemaker (1978), cuadros 2 y 5.

Por último, existen diferencias muy importantes entre Argentina y los otros dos países en cuanto a las tasas de participación en ocupaciones que requieren un grado apreciable de calificación, esto es, el grupo de las profesionales, técnicas y afines, a quienes se ha englobado conjuntamente con administradoras y funcionarias de categoría directiva y empleadas de oficina y personas en ocupaciones afines, por ser ocupaciones en general "modernas", que implican una organización capitalista y que de manera habitual corresponden, la mayoría de ellas, a estratos ocupacionales altos 
o relativamente altos. No es de extrañar que la participación en estas ocupaciones de las mujeres de 15 y más años sea bastante más del doble en Argentina que en Bolivia y Paraguay, pues aún en el empleo total (hombres y mujeres) la diferencia es notable $(17.2 \%$ del empleo total en Argentina; 5.9 en Bolivia y 10.1 en Paraguay). Sin duda, estas ocupaciones aumentan su tamaño relativo a medida que una economía se industrializa y se vuelve más compleja, lo que, como se ha visto, ha sucedido en mayor medida relativa en Argentina.

De este breve análisis comparativo de los tres países, puede concluirse que Argentina tiene la participación más elevada en ocupaciones no agrícolas y que, dentro de éstas, contribuyen a ese total más elevado, sobre todo, las tareas calificadas, pero también, en menor medida, las que están más abajo dentro de la escala social, como son las empleadas domésticas. Serían necesarios datos mucho más desagregados en los otros grupos ocupacionales -artesanas, operarias, jornaleras, etc. y en el grupo residual- para descubrir diferencias significativas que con toda seguridad estas agrupaciones ocultan. En el otro extremo, Bolivia debe su tasa tan elevada a la participación agrícola, diferenciándose muchísimo no sólo de Argentina sino también de Paraguay. Las diferencias en las ramas no agrícolas o en las ocupaciones no agrícolas, son, al lado de éstas, insignificantes. Sin embargo, cabe destacar la mayor importancia que presentaban las industrias manufactureras y el servicio doméstico en $\mathbf{P a}$ raguay en comparación con las de Bolivia (véanse los cuadros 3 y 4).

El cambio en las tasas refinadas de participación por sectores, ocupaciones y categoría ocupacional sólo puede ser analizado para los casos de Argentina y Paraguay (véanse los cuadros 3, 4 y 5). Surgen de nuevo algunas pautas que permiten observar similitudes más aparentes que reales entre ambos países, a la vez que aclaran cada uno de los casos en sí mismos.

Así, en Paraguay, se observa que las oscilaciones registradas entre las tres fechas estudiadas, mantienen una clara tendencia creciente cuando se considera, bien sea el total de sectores no agropecuarios o el total de ocupaciones no agrícolas - que engloban casi en su totalidad a los mismos grupos de trabajadores. En Argentina, en cambio, la tasa del total de trabajadoras no agrícolas (o casi la equivalente fuera del sector no agropecuario) tiene valores muy similares a la tasa del total (véanse los cuadros 3 y 4).

En Paraguay, la tendencia del grupo de ocupaciones que engloba a las artesanas, operarias y jornaleras (que en este país incluye a las vendedoras ambulantes) ${ }^{11}$ es muy similar a la del total — decreciente-, o sea que acompaña y contribuye a la disminución general, mientras que en la Argentina la tendencia también claramente decreciente de este grupo

11 Debe aclararse que en Paraguay, una parte considerable de estas ocupaciones se ejercen en áreas rurales, lo que con seguridad en Argentina se da en medida insignificante. 
es contrapuesta a la dirección ascendente del cambio total. De nuevo, una mayor desagregación de los datos en este grupo señalaría diferencias seguramente mayores, ya que es de suponer - entre otras razones por la reducida proporción de asalariadas en Paraguay - que en este país estas ocupaciones se realizan en mayor medida dentro del ámbito doméstico (producción artesanal), mientras que en la Argentina se llevaría a cabo sobre todo en empresas de tipo fabril. El descenso en este último caso guarda relación con la disminuciọ́n experimentada durante ese periodo del empleo en las industrias textiles, de confecciones y relacionadas, que son las que utilizan principalmente mano de obra femenina.

En ambos países el servicio doméstico tiene tendencias oscilantes y, por último, el grupo que engloba a las profesionales, administrativas y oficinistas es creciente en los dos, pero con nivel más elevado en Argentina, como ya se había señalado, y un aumento también más pronụnciado que en Paraguay.

Al desagregar por categorías ocupacionales - sólo se dispone de datos para las dos últimas fechas - aparece que, mientras que en la Argentina las asalariadas constituyen la gran mayoría de las trabajadoras y su aumento responde más bien a un aumento en el empleo total, en Paraguay, que en 1962 eran una proporción menor que las que trabajan por cuenta propia, el aumento observado en gran parte contrarresta la disminución de las primeras (véase el cuadro 5). De no mediar diferencias significativas importantes en las definiciones censales de las dos fechas, este fenómeno estaría señalando un cambio importante en la organización del trabajo en Paraguay.

\section{CONCLUSIONES}

La relación entre participación femenina y desarrollo económico ha sido formulada con frecuencia reiterada como una relación curvilínea, en forma de $U$. Es, sin lugar a dudas, uno de los esfuerzos más sostenidos en los estudios sobre mano de obra femenina por arribar a generalizaciones válidas. Sin embargo, se han encontrado casos que divergen con esa pauta, que prevendrían la generalización y estudios sincrónicos en que la conclusión sería la inexistencia de la relación. En esta investigación se apoya la tesis de que para una formulación adecuada de la relación -que, sin duda, existe, porque el trabajo femenino al igual que el masculino es parte del cambio social- es necesario calificarla y desagregar los niveles de análisis, ya que la participación femenina en el mercado de trabajo es un fenómeno complejo que es necesario desentrañar sin lugar a dudas. Una de las respuestas habituales dentro de esta temática a las inconsistencias encontradas - aparentes o reales- es que los datos son malos. En los casos estudiados no ha parecido que esa fuera la respuesta adecuada. Ni los procedimientos censales fueron muy dispares ni se trata 
de culturas muy diferentes. Pareció que lo adecuado era buscar otra vía de análisis.

Se trabajó sólo con uno de los términos de la relación, la participación femenina en la actividad económica, estudiada en tres países de América Latina con distinto grado de desarrollo, de la manera más desagregada que lo permitieron los datos existentes y los recursos disponibles, a lo largo de un periodo de casi un cuarto de siglo (lo implícito en el análisis es que hubo cambios socioeconómicos en el periodo en los tres casos, tal como se trató de mostrar a través de algunos indicadores). Sin tomar partido por la forma de la relación se ha podido ver que, a medida que se desagregaban los niveles de análisis, la interpretación de los diferenciales de participación de los tres países por una parte, y las pautas de cambio en cada país, por otra, se hacía más coherente.

En efecto, se partió de mediciones globales que al principio del periodo estudiado (alrededor de 1950) mostraban grandes diferencias entre Bolivia, por una parte, y Argentina y Paraguay, por otra y similitudes sorprendentes entre estos dos últimos casos - que se iban separando hacia 1970 - ya que se trata de países que, sin lugar a dudas, están en estadios muy diferentes de desarrollo económico. Sorprendía, asimismo, la enorme diferencia entre Bolivia y Paraguay - que se achica de manera considerable hacia 1975 - ya que las clasificaciones usuales de los países de la región según su grado de desarrollo económico los sitúan en estadios más bien semejantes. Por otra parte, las tendencias que muestran las medidas globales sugieren la afirmación simplista de que los tres casos serían una buena ejemplificación de la curva en $U$ : Bolivia, la fase de descenso; Paraguay, el punto más bajo de la participación (depresión de la curva), del que Argentina de manera clara estaría saliendo (fase ascendente).

Este confuso panorama se ha convertido, a través del presente análisis, en una visión más ordenada de la realidad y muestra que algunas veces las semejanzas son sólo aparentes, algunas otras, que las divergencias existen sólo en apariencia y aún otras, simplemente califican de modo conveniente el diferencial ya observado.

En efecto, la semejanza entre Argentina y Paraguay existe casi en exclusiva a nivel de la medida global, ya que en cuanto a las tendencias, en Argentina es claramente creciente mientras que en Paraguay es más bien oscilante. Ambos casos se diferencian no sólo en cuanto a las tendencias sino también en cuanto al nivel si se tienen en consideración las respectivas áreas urbanas. Paraguay pasa a presentar un mayor nivel de participación, estable, en contraposición a las mujeres urbanas argentinas, que parten de un nivel significativamente más bajo que las paraguayas, pero lo aumentan durante el periodo analizado. La tendencia al crecimiento en la participación global observada en la Argentina surge aún con más claridad en el comportamiento de las cohortes en edades centrales: en cualquier tramo del ciclo vital comprendido entre los 20 y 55 
años, las cohortes más jóvenes trabajan más que las más viejas y aún varias aumentan su participación entre 1960 y 1970 en edades maduras (por reentradas o entradas por primera vez a la actividad), en etapas en que usualmente se producen retiros. En Paraguay, por el contrario, el comportamiento es muy diferente. Por una parte, las cohortes disminuyen de manera menos abrupta que en la Argentina su participación al avanzar a lo largo del ciclo vital. Por otra parte, hay diferencias muy poco marcadas entre las cohortes más jóvenes y las más viejas al transitar por tramos equivalentes del ciclo vital. Estas diferencias tienen sin duda que ver con los tipos de ocupaciones prevalentes en una y otra sociedad, que permitiría a las mujeres paraguayas que necesitan ejercer una actividad remunerada una mayor permanencia en la misma (en gran parte trabajando por cuenta propia). En efecto, la mayor participación de las paraguayas, en comparación con las argentinas, como agricultoras por una parte y artesanas, operarias, etc., por otra -en gran parte efectuadas dentro del ámbito doméstico- permitiría ejercer a esas mujeres la actividad económica sin que eso signifique una ruptura necesaria con los roles femeninos tradicionales (ama de casa y madre). En la Argentina, la participación en ocupaciones de tipo profesional, administrativo, etc. - que en general suponen a más de cierto grado de calificación el ser ejercidas dentro una organización de tipo empresarial o gubernamental- es de manera notable más elevada que en Paraguay. Por otra parte, la participación en ocupaciones como operarias, artesanas, etc., no sólo es menor en Argentina que en Paraguay, sino que en la primera se realizan de manera preferente dentro de un tipo de organización fabril. Aún la participación en el servicio doméstico, de importancia cuantitativa semejante en los dos países, es posible que tenga características un tanto diferentes en ambos.

Las enormes diferencias observadas entre Bolivia y Paraguay, sobre todo al principio del periodo investigado, no sólo casi desaparecen hacia el final, sino que cambian de sentido cuando el análisis se refiere al área urbana. En efecto, las paraguayas urbanas presentaban tasas de participación algo más elevadas en 1972 que sus congéneres bolivianas en 1975. Son las bolivianas de áreas rurales - de manera principal en tareas agrícolas y como ayudas familiares- las que tienen una participación varias veces mayor que la de las paraguayas. En efecto, bien sea por razones de subsistencia, bien sea por una tradición cultural que se remonte al periodo incaico, parece responder a un hecho real y no a deficiencias de los datos el que las bolivianas de zonas rurales participen mucho más que las de Paraguay, Argentina y de la gran mayoría de los países latinoamericanos, donde posiblemente pese más la tradición hispánica que la indígena. Parece responder también al hecho real de que se ha producido un cambio importante en Bolivia después de 1950, con seguridad vinculado a la reforma agraria.

Por último, las diferencias entre Argentina y Bolivia se acentúan o más bien se delinean mejor al desagregar los niveles de análisis: la dife- 
rencia entre la participación en tareas agropecuarias en uno y otro país son aún más marcadas que cuando la comparación se efectúa entre Bolivia y Paraguay. También se hacen más pronunciadas, cuantitativamente, las diferencias al comparar la participación en ocupaciones no relacionadas con las tareas agrícolas. Alrededor de 1950, las argentinas participaban de manera significativa más que las bolivianas, sobre todo en tareas calificadas, como profesionales, administrativas, etc., pero también en servicio doméstico. No se ha contado con información para una fecha más cercana pero puede presuponerse que, aun cuando las diferencias se hayan reducido, deben continuar siendo todavía muy importantes.

En resumen, la actividad económica de las mujeres tiene no sólo niveles diferentes, sino también características y dinámicas muy diferentes en los tres países. Las diferencias y algunas de las semejanzas encontradas resultan casi imposible de ser expresadas, en el estadio presente del conocimiento, como una determinada forma de relación entre la participación y el desarrollo. Mucho queda por andar en el camino de la investigación para que esto pueda ser hecho. Los resultados presentes señalan varias líneas de análisis que prometen ser fructíferas.

En primer lugar, ya que la participación femenina es un fenómeno en esencia dinámico, este dinamismo se descubre en gran parte a través de la observación de datos puntuales analizados como historias de cohortes, cada una signada por los acontecimientos que le ha tocado vivir. El análisis de las cohortes puede enriquecerse al agregar más variables: estado civil, estructura familiar, educación, ocupaciones, etc. Podría así descubrirse cuáles son las mujeres (en términos de sus características) que aumentan o disminuyen sus propensiones a participar, por una parte $y$, por otra, cómo se insertan en el mercado de trabajo y los cambios que se producen en el mismo (cambios de ramas, ocupaciones, etc.).

Otra de las líneas que este estudio sugiere es la necesidad de analizar con mayor profundidad - con técnicas de tipo antropológico- ocupaciones específicas y los significados sociales que adquieren en las distintas sociedades. Por ejemplo, el servicio doméstico, las vendedoras ambulantes, las trabajadoras en la rama textil o de confecciones que trabajan o no por su cuenta, pero en relación con empresas de tipo capitalista, etc. Esto contribuiría, asimismo, a una mejor definición de "trabajo".

\section{REFERENCIAS BIBLIOGRÃFICAS}

Albo, Javier (1976), “Bodas de plata o réquiem por una reforma agraria?”, Revista Paraguaya de Sociología, 13 (35), enero-abril, pp. 25-28.

Argentina, Dirección Nacional del Servicio Estadístico, s.f.a., IV Censo General de la Nación. Tomo I, Censo de Población, Buenos Aires.

Argentina, Dirección Nacional de Estadística y Censo, s.f.b., Censo Nacional de Población 1960, Buenos Aires.

Argentina, Instituto Nacional de Estadística y Censo, s.f.c., "Censo Nacional de Población, Familias y Viviendas, 1970. Tabulados inéditos de la muestra del 2 por ciento". 
Arizpe, Lourdes (1976), "La mujer en el sector de trabajo informal en la Ciudad de México: ¿un caso de desempleo o de elección voluntaria?", Estudios de Población, Vol. I, No. 11, noviembre, pp. 627-645.

Banco Interamericano de Desarrollo (1973), Progreso económico y social en América Latina. Informe anual 1973, Washington, D. C.

Behm, Hugo y Fulvia Brizuela de Ramírez (1977), La mortalidad en los primeros años de vida en países de América Latina, Paraguay, 1967-1968, San José, CELADE - San José, Serie A, No. 1027.

Behm, Hugo, Ken Hill y Augusto Soliz (1977), La mortalidad en los primeros años de vida en países de América Latina, Bolivia 1971-1972, CELADE - San José, Serie A, No. 1025.

Bolivia, Dirección General de Estadística y Censos (1955), Censo demógráfico 1950, La Paz,

Bolivia, Instituto Nacional de Estadística (1975), "Cuadros de la Encuesta Demográfica Nacional de Bolivia" (no publicados).

Bolivia, Instituto Nacional de Estadística (1976), Boletín Estadistico, No. 20.

Boserup, Ester (1970), Woman's Role in Economic Development, George Allen and Unwin, Londres.

Boserup, Ester (1975), "Employment of Woman in Developing Countries", en León Tabah (Comp.): Population Growth and Economic Development in the Third World, Vol. 1, Cap. III, Ordina Editions, Dolhain, Belgica.

Brizuela de Ramírez, Fulvia y Juan Schoemaker (1978), La participación de las mujeres en la actividad económica en el Paraguay. Tendencia de la población económicamente activa femenina desde 1950 hasta 1972, Asunción, Centro Paraguayo de Estudios Sociológicos (Tomo II).

CELADE (1974), Boletín Demográfico, Año VII, No. 14.

CELADE, s.f., OMUECE 60 (Muestra del $4.91 \%$ del Censo del Paraguay, octubre de 1962), cuadros inéditos.

CEPAL (1972), "Estudio sobre la clasificación económica y social de los países de América Latina", Boletín Económico de América Latina, Vol. XVII, No. 2, segundo semestre, pp. 155-218.

Collver, O. Andrew y Eleanor Langlois (1962), "The Female Labor Force in Metropolitan Areas: an International Comparison", Economic Development and Cultural Change, 10 (4), pp. 367-385.

Corvalán y otros (1974), La población de Paraguay, Asunción, CICRED. Series.

Durand, John (1975), The Labor Force in Economic Development, Princeton, Princeton University Press.

Fucaraccio, Ángel (1974), "El trabajo femenino en Bolivia. Un estudio de caso" (informe provisional), CELADE, Santiago de Chile.

Jelin, Elizabeth (1977), "Migration and Labor Force Participation of Latin American Women: The Domestic Servants in the Cities", Signs, Vol. 3, 1 (129-141).

Leser, C. E. V. (1958): "Trends in Women's Work Participation", Population Studies, noviembre.

Morales, Juan A. y Carlos Machicado (1975), "Problemas y perspectivas del desarrollo económico boliviano y la integración andina", Revista de la Integración, VIII $(19 / 20)$, pp. 135-188.

Müller, María S., s.f., Tablas de mortalidad para Argentina, 1970 (Mimeo.).

Oppenheimer, V. K. (1970), The Female Labor Force in the United States, Demographic and Economic Factors Governing its Growth and Changing Composition, Berkeley, University of California, Population Monograph, Series No. 5.

Pantelides, Edith A. (1976), Estudio de la población femenina económicamente activa en América Latina, 1950-1970, Santiago, CELADE, Serie C, No. 161.

Paraguay, Dirección General de Estadística y Censos (1962), Censo de Población y Viviendas 1950, Asunción. 
Paraguay, Dirección General de Estadística y Censos (1966), Censo Nacional de Población y Viviendas 1962, Asunción.

Paraguay, Dirección General de Estadística y Censos (1975), Censo Nacional de Población y Viviendas 1972.

Recchini de Lattes, Zulma (1975), "Población económicamente activa", en Zulma Recchini de Lattes y Alfredo Lattes (Comps.), op. cit.

Recchini de Lattes, Zulma y Alfredo Lattes (Comps.) (1975), La población de Argentina, Buenos Aires, INDEC, Serie Investigaciones Demográficas I.

Recchini de Lattes, Zulma (1977), "Tamaño y características demográficas y socioeconómicas de la mano de obra femenina", en Zulma Recchini de Lattes, Ruth Sautu y Catalina Wainerman, La participación económica femenina en la Argentina desde la segunda posguerra hasta 1970 (Mimeo.).

Recchini de Lattes, Zulma y Catalina Wainerman (1977), "Empleo femenino y desarrollo económico: algunas evidencias”, Desarrollo Económico, No. 66, Vol. 17, julio-septiembre.

Romero Pittari, Salvador (1976), "Notas sobre la estratificación social en Bolivia", Revista Paraguaya de Sociología, 13 (35), enero-abril, pp. 7-23.

Schkolnik, Susana (1975), Mortalidad infantil en la Argentina a partir de la muestra del censo de 1970, Buenos Aires, INDEC, Serie Investigaciones Demográficas, 3.

Singer, Paul (1975), "Elementos para una teoría del empleo aplicable a países subdesarrollados", Seminario sobre Problemas del Empleo en América Latina, Grupo de Trabajo sobre Ocupación-Desocupación de CLACSO, La Plata, Argentina, 5-8 de marzo (Mimeo.).

Somoza, Jorge (1976), Encuesta Demográfica Nacional de Bolivia - Informe sobre aspectos demográficos, $\mathrm{La} \mathrm{Paz}$, Instituto Nacional de Estadística - Centro Latinoamericano de Demografía.

Torres P., Hugo (1977), La mujer boliviana y sus características demográficas en la fuerza de trabajo 1975, La Paz, Ediciones CIS, Serie Estudios de Población y Desarrollo No. 12.

Youssef, N. H. (1974), Women and Work in Developing Societies, Berkeley, University of California, Population Monograph Series, No. 15. 